\title{
Лингвистическая экспертиза
}

\author{
УДК 601.231:13
}

ББК 39.7 я24

DOI: $10.14529 /$ ling 160303

\section{ПРИЗНАКИ ЭКСТРЕМИСТСКОГО ТЕКСТА В РАБОТАХ НЕМЕЦКИХ ФИЛОСОФОВ}

\author{
А.Ю. Серебрякова \\ Южно-Уральский государственный университет, фрилиал в г. Златоусте
}

\begin{abstract}
В данной статье речь идет об экстремистском тексте, который рассматривается с точки зрения трех уровней его знаковой организации: синтактики, семантики и прагматики. С помощью многочисленных примеров автор демонстрирует признаки экстремизма в произведениях немецких философов на всех уровнях знаковой организации текста. Статья предназначена для студентов и аспирантов, занимающихся изучением вопросов межкультурной коммуникации.

Ключевые слова: экстремистский текст, прагматика, синтактика, семиотика, вербальность, враг, друг.
\end{abstract}

При анализе экстремистского текста важно учитывать не только его семантическую и синтаксическую организацию, но и прагматический аспект, который в данном случае является наиболее значимым. Под прагматикой принято понимать соотношение между текстом и его коммуникативными установками [4, с. 215]. Исследование прагматики экстремистского текста основывается в основном на оценке образно-смысловой картины интерпретируемого текста, в данном случае философского текста. Текстом принято называть осмысленную последовательность знаков разного рода. Экстремистский текст обладает всеми признаками обычного текста. Ими являются синтетический операторный способ, т. е. ориентация на слуховое и зрительное восприятие, особая сфера функционирования и синтетический тип функционирования, а именно временная и пространственная протяженность, непрерывность и изобразительность [1, с. 307].

Каждый текст обладает тремя уровнями знаковой организации: синтактикой, семантикой и прагматикой. Синтактика - это соотношение знаков разных систем в текстовом пространстве и временной последовательности. Семантика представляет собой соотношение материальной стороны знаков с содержанием текста, а прагматика осуществляет связь текста с его коммуникативными установками. Наша задача заключается в том, чтобы выявить признаки экстремизма в произведениях немецких философов (Ф. Ницше, Шопенгауэра и др.) на всех уровнях знаковой организации текста и выяснить, какой из этих уровней наиболее ярко демонстрирует эти признаки.

Синтаксический уровень текстов немецких философов не столь явно демонстрирует признаки экстремистского текста. Здесь нет большого количества графических и числовых символов, восклицательных предложений, призывов и авторских комментариев.

Что касается семантического уровня органи- зации текста, работы Ф. Ницше, А. Шопенгауэра и других немецких философов содержат достаточное количество признаков экстремистского текста. Семантический уровень любого экстремистского текста характеризуется главным образом контрастностью, которая облегчает восприятие и сводится к обозначению участников оппозиции и уточнению образов «враг - друг». Вариативность образов врага в экстремистском тексте достаточно широка и требует от воспринимающего дополнительного внимания к деталям текста. Так называемый язык вражды подчеркивает в плане логики идею противопоставления. Образ врага является основополагающим не только в анализируемых текстах, но и в экстремистском дискурсе в целом. Проблема самоидентификации и различения по принципу «мы - они», «свой - чужой», «друг враг», существует перед человеком и, конечно же, в первую очередь перед социальными группами с древнейших времен. По мнению большинства современных ученых, конструирование образа врага это один из наиболее важных и значимых механизмов формирования любой социальной группы. Общество способно сплотиться и укрепить свою идентичность в виде целостной «мы - группы» именно «по отношению к образу внешнего врага, обычно выступающего как «они - группа» [2, с. 68].

Контрастивность всегда выражается в противопоставлении на уровне классификации «свой чужой» и на уровне реакции «хороший - плохой», что сливаясь, образует единый оценочный образ «враг - друг», о котором говорилось выше. Настойчиво формируемый образа врага становится мощнейшим орудием манипуляции, настоящим пропагандистским мифом: известный феномен сплочения перед лицом угрозы является весьма эффективным для любой социальной общности, его часто используют лидеры групп для сохранения внутригруппового единства. 
Оценка содержания экстремистского текста заключается в выявлении актантов - участников оппозиции. А. Шопенгауэр в своем труде «Мир как воля и представление» предпринимает первую попытку противопоставить философию разума философии жизни. Часто его философию жизни называют философией воли. Все, что существует в мире, А. Шопенгауэр трактует как волю, волю к жизни. Главные актанты этой оппозиции «мировой разум» и «мировая воля» подкрепляются рядом антонимов, что можно продемонстрировать следующим образом.

\begin{tabular}{|c|c|}
\hline Мировой разум & Мировая воля \\
\hline $\begin{array}{c}\text { Рациональное, сознатель- } \\
\text { ное }\end{array}$ & $\begin{array}{c}\text { Иррациональное, бессоз- } \\
\text { нательное }\end{array}$ \\
\hline Стабильность & Спонтанность \\
\hline $\begin{array}{c}\text { Бытие (статическое } \\
\text { состояние) }\end{array}$ & Становление \\
\hline $\begin{array}{c}\text { Интеллектуальное искус- } \\
\text { ство Аполлона }\end{array}$ & $\begin{array}{c}\text { Жизненное искусство } \\
\text { Диониса }\end{array}$ \\
\hline
\end{tabular}

В отличие от Шопенгауэра Ф. Ницше трактует волю как «волю к власти», что становится центральным понятием философии Ницше. Жизнь согласно Ницше специфическая воля, которая аккумулирует все силы, чтобы добиться главной цели - власти. Рациональная деятельность не способствует повышению воли к власти, так как преобладание интеллекта парализует волю к власти, подменяя деятельность суждениями. Ницше отрицает христианскую мораль, которая, проповедуя любовь к ближнему человеку, подрывает волю к власти. Воля к власти превыше всех религиозных и моральных установок. Ницше предлагал произвести переоценку ценностей и возродить «мораль господ», заменив ею «мораль рабов», которую проповедует христианство. Это и послужило основой создания главной оппозиции в философии Ницше: «человек» и «сверхчеловек».

Субъект «морали господ», сверхчеловек, «белокурая бестия», является согласно Ницше представителем арийской расы, определенного нордического типа человека. Иными словами, Ницше проповедовал двойную мораль: по отношению к ближнему человеку - любовь, заботу и внимание, по отношению к чужому - необузданность зверя, в основе которой должны лежать инстинкты.

Таким образом, с точки зрения семантического уровня организации текста, работы Ф. Ницше содержат достаточное количество признаков экстремистского текста. Как уже говорилось выше, семантический уровень любого экстремистского текста характеризуется главным образом контрастностью, которая облегчает восприятие и сводится к обозначению участников оппозиции и уточнению образов «свой - чужой», «враг - друг». Тексты Ницше очень ярко демонстрируют наличие данной оппозиции, главными актантами которой являются, несомненно, «человек» и «сверхчеловек». Нам стало интересно проследить, как работают эти актанты в работе Ф. Ницше «Так говорил Заратустра», и с помощью каких сравнений и метафор эти актанты поддерживаются, образуя единый оценочный образ «свой - чужой».

Вариативность образов «человека» и «сверхчеловека» в экстремистских текстах Ницше достаточно широка. Возьмем конкретные предложения, взятые из работы Ф. Ницше «Так говорил Заратустра», и продемонстрируем все многообразие данных образов.

\begin{tabular}{|c|c|}
\hline Mensch & Übermensch \\
\hline Schlafende (спящий) & Erwachter (проснувшийся) \\
\hline $\begin{array}{c}\text { ein schmutziger Strom } \\
\text { (грязный поток) }\end{array}$ & ein Meer (море) \\
\hline Asche (прах ) & Feuer (огонь) \\
\hline Schmutz (грязь) & Glück (счастье) \\
\hline
\end{tabular}

\begin{tabular}{|c|c|}
\hline \multirow[t]{2}{*}{$\begin{array}{l}\text { Asche - Feuer } \\
\text { (прах - огонь) }\end{array}$} & $\begin{array}{l}\text { Damals trugst du deine Asche zu Berge: willst du heute dein Feuer in die Täler tragen? } \\
{[6, \text { c. } 278] .}\end{array}$ \\
\hline & $\begin{array}{l}\text { Тогда нес ты свой прах на гору; неужели теперь хочешь ты нести свой огонь в } \\
\text { долины? [5, с. 290]. }\end{array}$ \\
\hline \multirow{2}{*}{$\begin{array}{c}\text { Schlafende- Erwachter } \\
\text { Проснувшийся - спящий }\end{array}$} & ... ein Erwachter ist Zarathustra: was willst du nun bei den Schlafenden? [6, c. 278$].$ \\
\hline & Заратустра проснулся: чего же хочешь ты среди спящих? [5, с. 290]. \\
\hline \multirow[t]{2}{*}{ Schmutz - Gluck } & $\begin{array}{l}\text { Die Stunde, wo ihr sagt: «Was liegt an meinem Glücke! Es ist Armut und Schmutz und } \\
\text { ein erbärmliches Behagen. Aber mein Glück sollte das Dasein selber rechtfertigen!» [6, } \\
\text { c. } 279] \text {. }\end{array}$ \\
\hline & $\begin{array}{l}\text { Час, когда вы говорите: "В чем мое счастье! Оно - бедность и грязь, и жалкое } \\
\text { довольство собою. Мое счастье должно бы было оправдывать само существова- } \\
\text { ние!" [5, с. 290]. }\end{array}$ \\
\hline \multirow[t]{2}{*}{$\begin{array}{l}\text { eine schmerzliche Scham } \\
\quad-\text { Übermensch }\end{array}$} & $\begin{array}{l}\text { Was ist der Affe für den Menschen? Ein Gelächter oder eine schmerzliche Scham. Und } \\
\text { ebendas soll der Mensch für den Übermenschen sein: ein Gelächter oder eine schmer- } \\
\text { zliche Scham [6, c. 280]. }\end{array}$ \\
\hline & $\begin{array}{l}\text { Что такое обезьяна в отношении человека? Посмешище или мучительный по- } \\
\text { зор. И тем же самым должен быть человек для сверхчеловека: посмешищем или } \\
\text { мучительным позором [5, с. 292]. }\end{array}$ \\
\hline
\end{tabular}




\section{Лингвистическая экспертиза}

\begin{tabular}{|c|c|}
\hline \multirow[t]{2}{*}{ Der Leib - die Seele } & Einst blickte die Seele verächtlich auf den Leib... [6, c. 280]. \\
\hline & Некогда смотрела душа на тело с презрением... [5, с. 292]. \\
\hline \multirow[t]{2}{*}{$\begin{array}{c}\text { Ein schmutziger Strom - } \\
\text { ein Meer }\end{array}$} & $\begin{array}{l}\text { Wahrlich, ein schmutziger Strom ist der Mensch. Man muß schon ein Meer sein, } \\
\text { um einen schmutzigen Strom aufnehmen zu können, ohne unrein zu werden [6, c. } \\
\text { 281]. }\end{array}$ \\
\hline & $\begin{array}{l}\text { Поистине, человек - это грязный поток. Надо быть морем, чтобы принять в } \\
\text { себя грязный поток и не сделаться нечистым. } \\
\text { Смотрите, я учу вас о сверхчеловеке: он - это море, где может потонуть } \\
\text { ваше великое презрение [5, с. 293]. }\end{array}$ \\
\hline \multirow[t]{2}{*}{$\begin{array}{c}\text { Seil } \\
\text { (Brücke, Übergang) - } \\
\text { Zweck } \\
\text { Канат (мост, переход) - } \\
\text { цель }\end{array}$} & $\begin{array}{l}\text { Der Mensch ist ein Seil, geknüpft zwischen Tier und Übermensch-ein Seil über ei- } \\
\text { nem Abgrunde. Ein gefährliches Hinüber, ein gefährliches Auf-dem-Wege, ein } \\
\text { gefährliches Zurückblicken, ein gefährliches Schaudern und Stehenbleiben. Was groß } \\
\text { ist am Menschen, das ist, daß er eine Brücke und kein Zweck ist: was geliebt werden } \\
\text { kann am Menschen, das ist, daß er ein Übergang und ein Untergang ist. [6, c. 281]. }\end{array}$ \\
\hline & $\begin{array}{l}\text { Человек - это канат, натянутый между животным и сверхчеловеком, - ка- } \\
\text { нат над пропастью. } \\
\text { Опасно прохождение, опасно быть в пути, опасен взор, обращенный назад, } \\
\text { опасны страх и остановка. В человеке важно то, что он мост, а не цель: } \\
\text { человеке можно любить только то, что он переход и гибель [5, с. 293]. }\end{array}$ \\
\hline \multirow[t]{2}{*}{$\begin{array}{c}\text { ein Tropfen - Blitz (кап- } \\
\text { ля-молния) }\end{array}$} & $\begin{array}{l}\text { Seht, ich bin ein Verkündiger des Blitzes, und ein schwerer Tropfen aus der Wolke: } \\
\text { dieser Blitz aber heißt Übermensch [6, c. 283]. }\end{array}$ \\
\hline & $\begin{array}{l}\text { Смотрите, я провозвестник молнии и тяжелая капля из тучи; но эта молния } \\
\text { называется сверхчеловек. [5, с. 295]. }\end{array}$ \\
\hline \multirow{2}{*}{$\begin{array}{l}\text { Absterbende und selber } \\
\text { Vergiftete - uberreiches } \\
\text { Gestirn }\end{array}$} & $\begin{array}{l}\text { Verächter des Lebens sind es, Absterbende und selber Vergiftete, deren die Erde } \\
\text { müde ist: so mögen sie dahinfahren! [6, c. 283]. }\end{array}$ \\
\hline & $\begin{array}{l}\text { Они презирают жизнь, эти умирающие и сами себя отравившие, от кото- } \\
\text { рых устала земля: пусть же исчезнут они! [5, с. 295]. }\end{array}$ \\
\hline
\end{tabular}

Данные актанты имеют ряд типичных предикатов, которые еще более усиливают существующую оппозицию.

\begin{tabular}{|c|c|}
\hline $\begin{array}{c}\text { nach Wissen begehren } \\
\text { (жаждать знаний) }\end{array}$ & $\begin{array}{l}\text { müde sein seines Guten } \\
\text { (пресытиться) }\end{array}$ \\
\hline $\begin{array}{c}\text { sich an sein Werk } \\
\text { Machen (заниматься } \\
\text { своим делом) }\end{array}$ & $\begin{array}{l}\text { lachen uber j-n (смеять- } \\
\text { ся над кем-нибудь) }\end{array}$ \\
\hline Schenken (дарить) & $\begin{array}{c}\text { geizig sein } \\
\text { (быть жадным) }\end{array}$ \\
\hline Hören (слушать) & Schreien (кричать) \\
\hline $\begin{array}{c}\text { Schätze bringen (при- } \\
\text { носить дары) }\end{array}$ & Annehmen (принимать) \\
\hline $\begin{array}{l}\text { Mitleiden (сочувство- } \\
\text { вать) }\end{array}$ & $\begin{array}{l}\text { mißtraurisch sein } \\
\text { (не доверять) }\end{array}$ \\
\hline $\begin{array}{c}\text { Gott loben (хвалить } \\
\text { бога) }\end{array}$ & Brummen (ворчать) \\
\hline $\begin{array}{l}\text { Lieder Machen, singen } \\
\text { (петь песни) }\end{array}$ & Schlafen (спать) \\
\hline Geben (давать) & Betteln (просить) \\
\hline
\end{tabular}

Что касается прагматического уровня организации текста, Л.М. Голиков приписывает экстремистскому тексту 2 коммуникативные цели: принуждение к выполнению определенных действий и формирование внутреннего убеждения воспринимающего текст [3, с. 85].

Таким образом, мы можем сделать вывод, что работы Ф. Ницше и других немецких философов содержат достаточное количество призна- ков экстремистского текста. Главным семантическим признаком данных текстов является пропозициональное содержание, основанное на оппозиции «враг-друг», главными актантами рой в текстах Ницше являются «человек» и «сверхчеловек». Прагматический уровень текстов Ф. Ницше и других немецких философов характеризуется коммуникативным намерением принудить адресата к выполнению определенных действий и сформировать у него определенное внутреннее убеждение.

\section{Лuтература}

1. Баранов, А.Н. Лингвистическая экспертиза текста: теория и практика / А.Н. Баранов. М.: Наука, 2007. - 592 c.

2. Ворошилова, М.Б. Черная чума: номинации врага в экстремистском тексте / М.Б. Ворошилова // Юрислингвистика. - 2012. - № 1 (12). - C. 67-72.

3. Голиков, Л.М. Семиотика экстремистского текста / Л.М. Голиков // Юрислингвистика. - 2012. - № 1 (12). - C. 83-87.

4. Злоказов, К.В. Анализ особенностей восприятия креолизованного тектса деструктивно-экстремистской направленности / К.В. Злоказов // Политическая лингвистика. - 2011. - № 3. - С. 210-216.

5. Ницше, Ф. Так говорил Заратустра / Ф. Ницие; пер. Ю. Антоновского. - СПб.: Азбука. Азбука-Аттикус. 2011. - 461 c.

6. Nietzsche F. Also sprach Zaratustra / F. Nietzsche. -M.: Kapo, 2013. -448 c. 
Серебрякова Анна Юрьевна, кандидат филологических наук, доцент кафедры социальноправовых и гуманитарных наук, Южно-Уральский государственный университет, филиал в г. Златоусте, (Златоуст), serebrjakova_a@mail.ru

Поступила в редакцию 9 июня 2016 г.

DOI: $10.14529 /$ ling160303

\title{
SIGNS OF EXTREMIST TEXT IN THE WORKS OF GERMAN PHILOSOPHERS
}

\author{
A.Yu. Serebryakova, serebrjakova_a@mail.ru \\ South Ural State University, Zlatoust Branch, Zlatoust, Russian Federation
}

This article deals with extremist texts and three levels of its sign organization: syntactics, semiotics and pragmatics. The author illustrates signs of extremism in the works of German philosophers at all levels of the text organization. The article is meant for students and post-graduate students studying intercultural communication.

Keywords: extremist text, pragmatics, syntactics, verbalization, semiotics, enemy, friend.

\section{References}

1. Baranov A.N. Linguisticheskaia expertiza texta: theoriia i praktika [Linguistic Examination of the Text: Theory and Practice] Moscow, Nauka, 2007, 592 p.

2. Voroshilova M.B. Chernaia chuma: nominazii vraga v extremistskom texte [Black Plague: Category of the Enemy in an Extremist Text]. Yurislinguistika, 2012. No. 1 (12), pp. 67-72.

3. Golikov L.M. Semiotika extremistskogo texta [Semiotics of the Extremist text]. Yurislinguistika, 2012. No. 1 (12), 83-87 p.

4. Zlokazov K.V. Analiz vospriiatiia kreolizovannogo texta destruktivno-extremistskoi napravlennosti [Perception Analysis of the Creolized Destructive Extremist Text]. Politicheskaia linguistika, 2011. No. 3, pp. 210216.

5. Nizshe F. Tak govoril Zaratustra. Perevod Yu. Antonovskogo. St. Petersburg, Azbuka-Attikus Publ., 2011, $461 \mathrm{p}$.

6. Nizshe F. Tak govoril Zaratustra. Moscow, Karo Publ., 2013, 448 p.

Anna Yurievna Serebryakova, Candidate of Philology, Assistant Professor of the Department of SocialLaw sciences and Humanities of the South Ural State University, Zlatoust Branch, serebrjakova_a@mail.ru

Received 9 June 2016

\section{ОБРАЗЕЦ ЦИТИРОВАНИЯ}

Серебрякова, А.Ю. Признаки экстремистского текста в работах немецких философов / А.Ю. Серебрякова // Вестник ЮУрГУ. Серия «Лингвистика». - 2016. - Т. 13, № 3. - C. 18-21. DOI: $10.14529 /$ ling160303

\section{FOR CITATION}

Serebryakova A.Yu. Signs of Extremist Text in the Works of German Philosophers. Bulletin of the South Ural State University. Ser. Linguistics. 2016, vol. 13, no. 3, pp. 18-21. (in Russ.). DOI: 10.14529/ling160303 